\title{
The involvement of XPC protein in the cisplatin DNA damaging treat- ment-mediated cellular response
}

\author{
Gan WANG*, Alan DOMBKOWSKI, Lynn CHUANG, Xiao Xin S XU \\ Institute of Environmental Health Sciences, Wayne State University, 2727 Second Avenue, Detroit, MI 48201, USA
}

\begin{abstract}
Recognition of DNA damage is a critical step for DNA damage-mediated cellular response. XPC is an important DNA damage recognition protein involved in nucleotide excision repair (NER). We have studied the XPC protein in cisplatin DNA damaging treatment-mediated cellular response. Comparison of the microarray data from both normal and XPCdefective human fibroblasts identified 861 XPC-responsive genes in the cisplatin treatment (with minimum fold change $\geq 1.5$ ). The cell cycle and cell proliferation-related genes are the most affected genes by the XPC defect in the treatment. Many other cellular function genes, especially the DNA repair and signal transduction-related genes, were also affected by the XPC defect in the treatment. To validate the microarray data, the transcription levels of some microarray-identified genes were also determined by an RT-PCR based real time PCR assay. The real time PCR results are consistent with the microarray data for most of the tested genes, indicating the reliability of the microarray data. To further validate the microarray data, the cisplatin treatment-mediated caspase-3 activation was also determined. The Western blot hybridization results indicate that the XPC defect greatly attenuates the cisplatin treatment-mediated Caspase- 3 activation. We elucidated the role of $\mathrm{p} 53$ protein in the XPC protein DNA damage recognition-mediated signaling process. The XPC defect reduces the cisplatin treatment-mediated $\mathrm{p} 53$ response. These results suggest that the XPC protein plays an important role in the cisplatin treatment-mediated cellular response. It may also suggest a possible mechanism of cancer cell drug resistance.
\end{abstract}

Keywords: XPC, cisplatin DNA-damaging treatment, microarray analysis.

\section{INTRODUCTION}

In living cells, genomic DNA is constantly being damaged by both endogenous and environmental factors. The recognition of DNA damage plays an important role in eliminating the damage and maintaining genetic integrity [1-4]. The signal resulting from DNA damage recognition leads to either the damage removal (DNA repair) or cell death of the damaged cells (apoptosis) [5, 6]. However, if DNA damage cannot be recognized because of defects in the DNA damage recognition, a high risk of mutation will result. Mutations can lead to many disease conditions including genetic, cancerous, and age-related diseases. In addition, the inability to recognize DNA damage may also be associated with cancer cell drug resistance.

$\mathrm{XPC}$ is an important DNA damage recognition protein involved in global genome DNA repair (GGR), a subfamily of nucleotide excision repair (NER) $[7,8]$. The XPC

*Corresponding author: Gan WANG

Tel: 313-964-8140, Fax: 313-577-0082;

E-mail: g.wang@wayne.edu protein recognizes a variety of bulky DNA damages including UV-caused cyclobutane pyrimidine dimers and cisplatin-generated interstrand crosslinks (ICL) [9-16]. The XPC protein binds tightly with an HR23B protein to form a stable XPC-HR23B complex [17-19]. The XPC protein also interacts with several other important protein components including the basal transcription factor TFIIH and the centrisomal protein CEN2 [18-22]. Recent studies identified the XPC-HR23B complex as the first protein component that recognizes and binds to the damaged sites [23-25]. Interestingly, XPC defects have been associated with many types of cancer [26-29]. Transgenic mice studies also revealed the predisposition of many types of cancer in the XPC gene knockout mice [30-32]. All these results strongly suggest that the XPC protein plays an important role in prevention of the DNA damage-mediated cancer occurrence. However, the precise role of the XPC protein in these processes remains unclear.

In this work, we have studied the involvement of the XPC protein in cisplatin DNA damaging treatment-mediated cellular response. Both our microarray data and the caspase- 3 activation results suggest that the XPC protein 
plays a crucial role in the cisplatin DNA damaging treatment-mediated cellular response by causing cell cycle arrest, which allows for DNA repair and apoptosis; and that the XPC defect causes damaged cells to escape from DNA repair and apoptosis, leading to an increase in mutation accumulation and a high risk in disease development.

\section{MATERIALS AND METHODS}

\section{Cell lines}

The human normal fibroblast (NF) cells (GM00043) and the xeroderma pigmentosum group C (XPC) cells (GM16684 and GM02096) were obtained from the NIGMS Human Genetic Cell Repository (Corriel Institute, Camden, NJ). The GM16684 XPC cells carry a two base pair deletion in exon 5 (del AT 669-670), which results in a truncated XPC protein with the N-terminal 200 amino acid residues. The GM02096 XPC cells carry a point mutation in the XPC gene that converts the proline at position 218 to histidine. Both the NF and XPC cells were maintained in MEM medium supplemented with $20 \%$ FBS, $2 \times$ essential amino acids, nonessential amino acids, and vitamins.

\section{Cisplatin treatment and RNA preparation}

Both cell lines were grown in cell growth medium at $37^{\circ} \mathrm{C}$ (with $5 \% \mathrm{CO}_{2}$ ) to approximately $70 \%$ confluence. Cisplatin (Sigma Corp., St. Louis, MO) was freshly dissolved into dimethyl sulfoxide (DMSO) $(20 \mathrm{mg} / \mathrm{ml})$ and added to the cell culture medium to a final concentration of $10 \mu \mathrm{M}$. The cells were incubated at $37^{\circ} \mathrm{C}$ for $16 \mathrm{~h}$ and harvested from the flasks. Total RNA was isolated from the treated cells using a Qiagen RNeasy Purification Kit (Qiagen, Valencia, CA). RNAs isolated from three individual treatments were mixed. As a control, total RNA was also isolated from the NF and XPC cells that were treated with DMSO alone using a similar method. The quality of the isolated RNA was determined by an Agilent 2100 Bioanalyzer (Agilent Technologies, Wilmington, DE).

\section{Microarray assay}

The RNAs isolated from both untreated and cisplatin-treated NF and XPC cells were individually labeled with a Cy5 fluorescence in a reverse transcription reaction $\left(42^{\circ} \mathrm{C}\right.$ for $\left.1 \mathrm{~h}\right)$ to generate fluorescence-labeled cDNA probes. A Universal Human RNA Reference Sample (Stratagene, La Jolla, CA) was labeled with a Cy3 fluorescence in a similar reaction. The $\mathrm{Cy} 3$ and $\mathrm{Cy} 5$ labeled cDNA probes were mixed together and cleaned using a Qiaquick PCR Purification Kit (Qiagen). The fluorescence-labeled cDNA probes were added to the Agilent Human 1 cDNA Microarray slides, which contained 12,814 unique human cDNA clones (Agilent Technologies), for a competitive hybridization $\left(65^{\circ} \mathrm{C}\right.$ for $\left.17 \mathrm{~h}\right)$. Each RNA sample was hybridized with three microarray slides. The slides were scanned using an Agilent two-color laser detection scanner. The two-color image was feature-extracted using Agilent's Feature Extraction software. The fluorescent intensities were normalized using Local Weighted Regression Scatter Plot Smoothing (LOWESS) intensity-dependent normalization.

\section{The microarray data management and analysis}

The image obtained from the two-color scanner was analyzed by Significance Analysis of Microarray Data (SAM) software (devel- oped at Stanford University) to identify the genes with significant alterations in their transcriptions. Within each cell line, genes differentially expressed in response to the treatment were identified using the replicate microarray data and a permutation-based statistical test with an estimated false discovery rate of 5\% [33]. The following formula was used to determine the fold change $(\Delta)$ in the same cell line between the treated and untreated cells:

$$
\log _{2} \Delta=\log _{2}\left(\frac{S_{2}}{R}\right)-\log _{2}\left(-\frac{S_{1}}{R}\right)
$$

In this formula, $\mathrm{S} 1$ and $\mathrm{S} 2$ represent the fluorescence signals of the untreated and cisplatin-treated RNA samples in the microarrays of the same cell line, $\mathrm{R}$ represents the fluorescence signal of the reference sample detected in these microarrays. If the $\Delta<1$, then it is expressed as $1 / \Delta$ or a negative number.

The genes that were affected by the XPC protein DNA damage recognition signal were further determined by the net fold change $(\Delta \Delta)$ of the same gene between the XPC and the NF cells using the following formula:

$$
\log _{2} \Delta \Delta=\left|\log _{2} \Delta \mathrm{XPC}-\log _{2} \Delta \mathrm{NF}\right| \geq \log _{2} 1.5
$$

It is worth mentioning that

$$
\begin{aligned}
& \log _{2} \Delta \mathrm{XPC}-\log _{2} \Delta \mathrm{NF}
\end{aligned}
$$

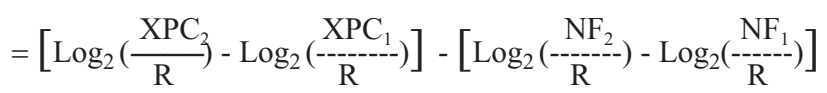

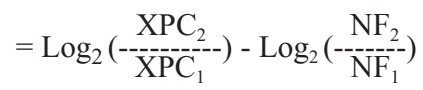

$$
\begin{aligned}
& =\log _{2}\left(\frac{\mathrm{XPC}_{2} / \mathrm{XPC}_{1}}{\mathrm{NF} 2 / \mathrm{NF} 1}\right)
\end{aligned}
$$

The genes identified as statistically significant with the SAM were further analyzed by the Expression Analysis Systematic Explorer (EASE) software to categorize into biological pathways and gene ontologies (GO consortium).

\section{Real time RT-PCR}

The reverse transcription (RT) reaction was carried out using $2 \mu \mathrm{g}$ of total RNA following the protocol for the Taqman Reverse Transcription Master Mix (Applied Biosystems, Foster City, CA). A primer optimization step is tested for each set of primers to determine the ideal primer concentrations. A primer matrix is performed using primer concentration of $50 \mathrm{nM}, 300 \mathrm{nM}$ and $900 \mathrm{nM}$. After optimal primer concentrations are determined, $10 \mathrm{ng}$ of cDNA samples were used for the PCR reaction and analyzed using the ABI Prism 7000 Sequence Detection System (Applied Biosystems). Sybr Green was used as a detector for monitoring the amplified double-stranded DNA fragments. Cycle threshold $(\mathrm{Ct})$ values were obtained from the ABI Prism 7000 software and the fold change was determined. As a control, the mRNA level of the GAPDH gene was also determined in the real time PCR assay for each RNA sample and used to minimize the experimental variations.

\section{Western blot hybridization assay}

The p53 (Pab1801) and caspase-3 (H-277) antibodies were purchased from Santa Cruz Biotechnologies (Santa Cruz, CA). Both the NF and XPC cells were treated with $20 \mu \mathrm{M}$ cisplatin. At various 
time points the cells were harvested and lysed in RIPA cell lysis buffer $(1 \times$ PBS, $1 \%$ NP-40 (v/v), 0.5\% Deoxycholic acid (w/v), $0.1 \%$ SDS (w/v)). The cell lyses (30 $\mu \mathrm{g}$ total protein) was mixed in $20 \mu \mathrm{l}$ of solution containing $1 \times$ SDS gel loading buffer $(60 \mathrm{mM}$ Tris, $\mathrm{pH}$ $6.8,1 \%$ SDS, $1 \%$ 2-mercaptoethanol (v/v), 10\% glycerol (v/v), and $0.1 \%$ bromophenol blue $(\mathrm{w} / \mathrm{v}))$ and boiled for $10 \mathrm{~min}$. The cell lyses were analyzed by SDS-PAGE. The proteins were transferred to a PVDF membrane and hybridized with the desired primary antibodies, followed by suitable secondary antibodies. The ECL reagent (Amersham, Arlington Heights, IL) was used to detect the desired proteins in the membrane. The same membrane was then stripped in a stripping solution (62.5 mM Tris, $\mathrm{pH} 6.8,2 \% \mathrm{SDS}(\mathrm{v} / \mathrm{v}), 0.7 \%$ 2-mercaptoe-thanol (v/v)) and hybridized with the Tubulin antibody (T5168 from Sigma Corp.) to determine the level of Tubulin in each sample. The level of the desired proteins was calculated to the relative level of Tubulin in each sample to minimize the experimental variations.

\section{RESULTS}

\section{Rationale}

To study the involvement of the XPC protein in cisplatin DNA damaging treatment-mediated cellular response, it is important to determine the genes that are affected by the XPC protein DNA damage recognition signal in the treatment. The GM16684 XPC cells carry a truncated XPC protein that retains only the N-terminal $\sim 200$ amino acid residues. Since both the DNA binding domain and the protein-protein interaction domains (both the XPC-HR23B and the XPC-TFIIH binding domains) of the XPC protein are located at the $\mathrm{C}$-terminal region of the protein (around the 400-750 amino acid region) [34], the GM16684 XPC cell line lacks a functional XPC protein and is ideal for the study. In addition, the microarray assay also provides an opportunity for determining the transcription levels in thousands of genes in a single experiment. We take advantage of both the microarray assay and the XPC-defective XPC cells to determine the genes that are affected by the XPC protein DNA damage recognition signal. To minimize the experimental variations, the cells were treated in several independent experiments and the RNA isolated from these experiments were mixed and used as a template for the microarray assay. To reduce the technical variations of the microarray assay, each RNA sample was hybridized with three arrays and only data that were reliable and with no flag-out outliers in at least two of the three arrays were used in our data analysis. To minimize the error resulting from the non-isogenisity of cell lines, the microarray assay was also performed on two separate XPC cells lines for comparison of the commonly affected genes. The primary microarray data analysis was focused on the GM16684 XPC cells because of a unique XPC gene mutation carried in this cell line. Using these carefully designed experiments, satisfactory results were obtained from our microarray experiments. In the total of 18,564 spots contained in the

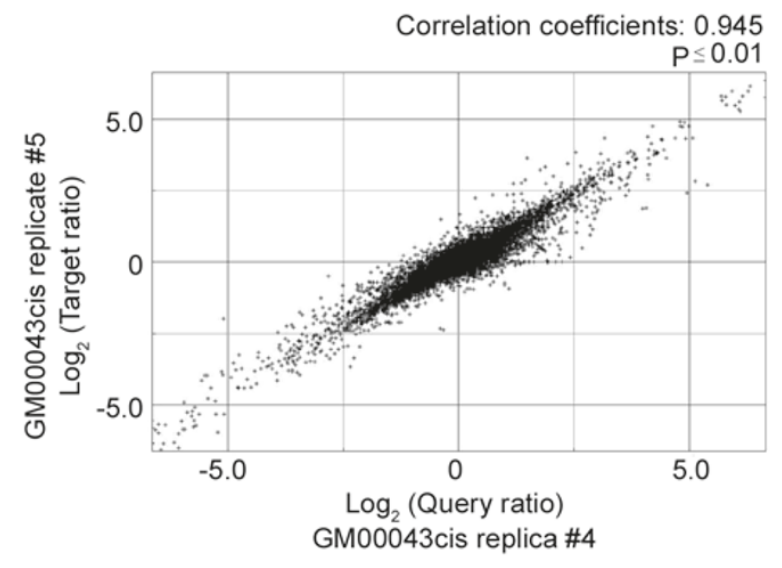

Fig. 1 The reproducibility of the microarray data. Two microarrays were performed with the same RNA sample (cisplatin-treated GM00043 RNA), providing a comparison of technical replicates. The RNA sample was labeled with Cy5, and a common reference sample was labeled with Cy3. The labeled samples were co-hybridized on both arrays. The axes represent the $\log _{2}$ (Cy5/Cy3) for each replicate array. Each spot represents one gene on the Agilent Human 1 cDNA array.

microarray, valuable data was extracted from between 94\%-98\% of the outliers in both the NF and XPC RNA samples. A linear correlation of 0.945 indicates a very high reproducibility of our microarray data in the cisplatintreated NF cells as shown in Fig. 1.

\section{Identification of the genes that are affected by the XPC defects in the cisplatin treatment}

Since the results obtained from our microarray assay showed a high reproducibility of the data, we further determined the genes that are affected by the XPC defect in the cisplatin treatment. The data obtained from the microarray assay was analyzed first by SAM to identify the genes with a significant alteration in their transcriptions in both the NF and XPC cells with an estimated 5\% false discovery rate. The genes that are regulated by the XPC protein were further determined by comparison of the altered genes between the XPC and NF cells with a minimal 1.5 -fold net change $(\mathrm{p} \leq 0.01)$. In the GM16684 XPC cells, a total of 1,155 genes passed the statistical analysis and showed significant alterations in their transcription levels. These genes were further analyzed by EASE software to determine their biological pathways and gene ontologies. Out of the total of 1,155 genes identified in the GM16684 XPC cells, 861 genes were mapped onto known biological pathways and gene ontologies with the EASE analysis (Tab. 1) [35]. In GM02096 XPC cells, a total of 731 genes were identified as XPC-responsive genes by the microarray data analysis. Comparison of the XPC-responsive genes in 
Tab 1. Characterization of some of the genes affected by the XPC defect in the cisplatin treatment ${ }^{\mathrm{a}}$

\begin{tabular}{|c|c|c|c|c|c|}
\hline Gene Category & $\begin{array}{l}\text { List } \\
\text { Hits } \\
\end{array}$ & $\begin{array}{r}\text { List } \\
\text { Total }\end{array}$ & $\begin{array}{c}\text { Population } \\
\text { Hits } \\
\end{array}$ & $\begin{array}{c}\text { Population } \\
\text { Total } \\
\end{array}$ & $\begin{array}{l}\text { EASE } \\
\text { score }\end{array}$ \\
\hline Mitotic cell cycle & 64 & 861 & 206 & 6383 & $6.96 \mathrm{e}-011$ \\
\hline Cell proliferation & 142 & 861 & 632 & 6383 & $9.25 \mathrm{e}-011$ \\
\hline Cell cycle & 102 & 861 & 412 & 6383 & $2.90 \mathrm{e}-010$ \\
\hline Regulation of cell cycle & 64 & 861 & 227 & 6383 & $5.55 \mathrm{e}-009$ \\
\hline Mitosis & 29 & 861 & 82 & 6383 & $1.33 \mathrm{e}-006$ \\
\hline Cell growth/maintenance & 340 & 861 & 2071 & 6383 & $2.14 \mathrm{e}-006$ \\
\hline M phase mitotic cell cycle & 29 & 861 & 84 & 6383 & $2.30 \mathrm{e}-006$ \\
\hline Nuclear division & 31 & 861 & 102 & 6383 & $1.75 \mathrm{e}-005$ \\
\hline M phase & 32 & 861 & 107 & 6383 & $1.78 \mathrm{e}-005$ \\
\hline Cellular process & 532 & 861 & 3534 & 6383 & $2.82 \mathrm{e}-005$ \\
\hline $\begin{array}{l}\mathrm{G} 2 / \mathrm{M} \text { transition of } \\
\text { mitotic cell cycle }\end{array}$ & 13 & 861 & 27 & 6383 & $8.24 \mathrm{e}-005$ \\
\hline $\begin{array}{l}\text { DNA replication and } \\
\text { chromosome cycle }\end{array}$ & 30 & 861 & 107 & 6383 & $1.25 \mathrm{e}-004$ \\
\hline Response external stimulus & 133 & 861 & 741 & 6383 & $2.24 \mathrm{e}-004$ \\
\hline Regulation cell proliferation & 38 & 861 & 158 & 6383 & $4.5 \mathrm{e}-004$ \\
\hline Defense response & 93 & 861 & 496 & 6383 & $5.71 \mathrm{e}-004$ \\
\hline Cell cycle checkpoint & 10 & 861 & 20 & 6383 & $5.85 \mathrm{e}-004$ \\
\hline Response to stress & 77 & 861 & 398 & 6383 & $7.35 \mathrm{e}-004$ \\
\hline G1 phase mitotic cell cycle & 7 & 861 & 9 & 6383 & $3.44 \mathrm{e}-004$ \\
\hline S phase mitotic cell cycle & 24 & 861 & 86 & 6383 & $7.48 \mathrm{e}-004$ \\
\hline DNA metabolism & 58 & 861 & 284 & 6383 & $1.01 \mathrm{e}-003$ \\
\hline Regulation of CDK activity & 10 & 861 & 22 & 6383 & $1.35 \mathrm{e}-003$ \\
\hline DNA replication & 23 & 861 & 85 & 6383 & $1.54 \mathrm{e}-003$ \\
\hline Phosphate metabolism & 83 & 861 & 450 & 6383 & $1.95 \mathrm{e}-003$ \\
\hline Hemostasis & 18 & 861 & 62 & 6383 & $2.65 \mathrm{e}-003$ \\
\hline G1/S transition & 13 & 861 & 38 & 6383 & $3.11 \mathrm{e}-003$ \\
\hline DNA repair & 27 & 861 & 112 & 6383 & $3.26 \mathrm{e}-003$ \\
\hline Regulation of mitosis & 8 & 861 & 17 & 6383 & $4.47 \mathrm{e}-003$ \\
\hline Dephosphorylation & 21 & 861 & 88 & 6383 & $1.17 \mathrm{e}-002$ \\
\hline Protein modification & 102 & 861 & 608 & 6383 & $1.15 \mathrm{e}-002$ \\
\hline Signal transduction & 215 & 861 & 1409 & 6383 & $1.91 \mathrm{e}-002$ \\
\hline Phosphorylation & 59 & 861 & 350 & 6383 & $5.07 \mathrm{e}-002$ \\
\hline Cell cycle arrest & 8 & 861 & 27 & 6383 & $6.15 \mathrm{e}-002$ \\
\hline Apoptotic program & 7 & 861 & 22 & 6383 & $6.54 \mathrm{e}-002$ \\
\hline Mismatch repair & 5 & 861 & 12 & 6383 & $6.65 \mathrm{e}-002$ \\
\hline Response to DNA damage & 8 & 861 & 31 & 6383 & $1.14 \mathrm{e}-001$ \\
\hline Caspase activation & 3 & 861 & 7 & 6383 & $2.41 \mathrm{e}-001$ \\
\hline
\end{tabular}

a (characterization of whole list of the common genes are provided as online supplementation) 
Tab. 2 Determination of the gene transcription alteration in both the NF and XPC cells by the real time PCR assay

\begin{tabular}{|c|c|c|c|c|c|c|c|c|}
\hline \multirow{2}{*}{ Gene } & \multicolumn{4}{|c|}{ NF cells (GM00043) } & \multicolumn{4}{|c|}{ XPC cells (GM16684) } \\
\hline & $\mathrm{Ct}^{*}$ (untreated) & $\mathrm{Ct}$ (treated) & $\Delta \mathrm{Ct}^{* *}$ & Fold change $^{* * *}$ & $\mathrm{Ct}$ (untreated) & $\mathrm{Ct}$ (treated) & $\Delta \mathrm{Ct}$ & Fold change \\
\hline$c d c 4$ & 26.65 & $28.46-1.81$ & & -3.51 & 32.11 & 29.92 & 2.19 & 4.56 \\
\hline$c d k 1$ & 22.29 & 23.76 & -1.47 & -2.77 & 25.17 & 25.59 & -0.42 & -1.34 \\
\hline$c d k 2$ & 23.42 & 23.38 & 0.04 & 1.03 & 26.13 & 24.87 & 1.26 & 2.39 \\
\hline$c y c A 2$ & 22.04 & 22.78 & -0.74 & -1.67 & 25.42 & 25.21 & 0.21 & 1.15 \\
\hline$c y c D 2$ & 32.62 & 32.52 & 0.1 & 1.07 & 25.31 & 26.01 & -0.7 & -1.62 \\
\hline$c y c E 1$ & 27.22 & 26.69 & 0.53 & 1.44 & 29.17 & 27.85 & 1.32 & 2.50 \\
\hline $\operatorname{cipl}(p 21)$ & 21.57 & 18.31 & 3.26 & 9.58 & 20.00 & 18.80 & 1.20 & 2.30 \\
\hline$I A P 1$ & 31.58 & 31.69 & -0.11 & -1.08 & 30.57 & 30.03 & 0.54 & 1.45 \\
\hline$m \operatorname{lh} 1$ & 28.74 & 29.67 & -0.93 & -1.91 & 28.69 & 27.87 & 0.82 & 1.77 \\
\hline$m s h 2$ & 24.79 & 25.51 & -0.72 & -1.65 & 26.69 & 26.13 & 0.56 & 1.47 \\
\hline$P C N A$ & 23.23 & 23.23 & 0 & 1 & 25.40 & 24.52 & 0.88 & 1.84 \\
\hline$P L K$ & 25.47 & 26.55 & -1.08 & -2.11 & 28.63 & 28.72 & -0.09 & -1.06 \\
\hline$P P M I D$ & 25.65 & 24.11 & 1.54 & 2.91 & 25.50 & 25.28 & 0.22 & 1.16 \\
\hline$x p c$ & 27.86 & 26.16 & 1.70 & 3.25 & 27.96 & 28.54 & -0.58 & -1.49 \\
\hline
\end{tabular}

*The Ct (Cycle threshold) value was obtained from the ABI Prism 7000 software.

${ }^{* *}$ The $\Delta \mathrm{Ct}$ value was calculated as $\mathrm{Ct}$ (treated)-Ct (untreated).

${ }^{* * *}$ The Fold change was calculated either as $2^{\Delta \mathrm{Ct}}$ (if $\left.\Delta \mathrm{Ct}>0\right)$ or $1 / 2^{\Delta \mathrm{Ct}}($ if $\Delta \mathrm{Ct}<0)$.

both the GM16684 and GM02096 XPC cells indicated that 485 of these genes were common in both XPC cell lines (data not shown). The EASE analysis result also indicated that these common XPC-responsive genes were mapped to similar biological pathways and gene ontologies as those genes identified in the GM16684 or GM02096 XPC cell line alone (data not shown).

\section{Determining the level of gene transcription by an RT-PCR based real time PCR assay}

The results obtained from the microarray data analysis revealed the altered transcriptions of many genes by the XPC defect in the cisplatin treatment. To validate the microarray data, we further determined the transcription levels in some of the microarray-identified XPC-responsive genes in both the NF and GM16684 XPC cells using an RT-PCR based real time PCR assay (Tab. 2). The genes that were tested by the real time PCR assay were cell cycle and DNA repair-related genes, including $c y c E 1, c d c 45, c y c A 2$, cycD2, cdk1, cdk2, cip1, IAP1, mlh1, msh2, PCNA, PLK, $P P M 1 D$, and $x p c$. In the 14 genes tested by the real time PCR assay, 12 genes showed similar transcription alteration patterns between the real time PCR and the microarray assays, suggesting a very high reliability of the microarray data obtained in this study.

\section{The role of the XPC protein in the cisplatin DNA damaging treatment-mediated cell cycle arrest}

The results obtained from the EASE analysis revealed that the genes related to cell cycle and cell proliferation functions were affected to a greater extent by the XPC defects in the cisplatin treatment than genes related to other cellular functions, suggesting a very important role of the XPC protein in the cisplatin DNA damaging treatment-mediated cell cycle arrest and apoptosis. To further determine the effect of the XPC defects in the cisplatin treatment-mediated cell cycle regulation, we analyzed the gene expression profiles of the cell cycle-related genes in both NF and GM16684 XPC cells (Fig. 2 and Tab. 3). The levels of transcription for many cell cycle-related genes were significantly affected by the XPC defects in the treatment. In NF cells, for example, many cell cycle-related genes, including $c y c A 2, c y c B 1, c y c D 2, c y c E 1, c d k 1$, $c d k 2, c d k 6, c d c 7, c d c 25 A, c d c 25 B, c d c 45, c d c 61$, and PLK (Serine/Threomine-protein kinase), were down-regulated with the cisplatin treatment. The degrees of down-regulation of these genes, however, were attenuated in the cisplatin-treated GM16684 XPC cells (Tab. 3). Several 


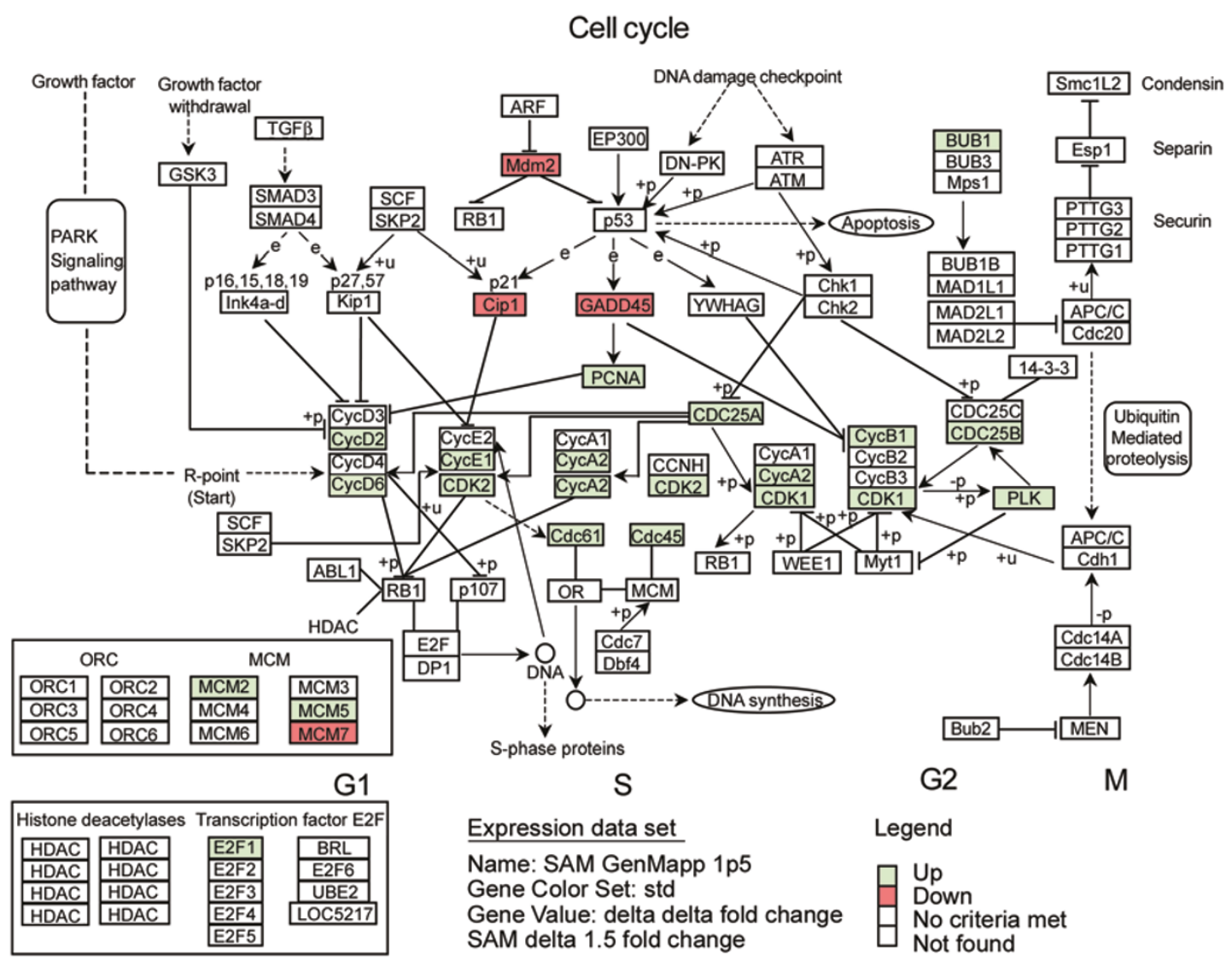

Fig 2. The effect of the XPC defect on transcription of cell cycle-related genes in the cisplatin treatment. The net fold change of genes $(\Delta \Delta)$ between the XPC and NF cells with the cisplatin treatment was used to determine the pattern of gene transcription regulation $(\Delta \Delta \geq 1.5)$. If the $\Delta \Delta>0$, the gene is counted as up regulated (colored green in the map). If the $\Delta \Delta<0$, the gene is counted as down regulated (colored red in the map). If the $\Delta \Delta<1.5$ or if no data is available from the microarray analysis, the gene is uncolored in the map.

cell cycle regulating genes, including cip1 (p21), $m d m 2$, and GADD 45 (growth arrest and DNA-damaged-inducible protein GADD45 $\alpha$ ), were up-regulated in the treated NF cells; in contrast, the degree of up-regulation of these genes was attenuated in the treated GM16684 XPC cells (Tab. 3). These results suggest that the XPC protein plays a very important role in the cisplatin DNA damaging treatmentmediated cell cycle regulation and that the XPC defect results in the cell's inability to regulate many cell cycle-related genes in the treatment.

\section{The role of the XPC protein in the cisplatin DNA damaging treatment-mediated apoptosis}

The results obtained from our microarray data analysis also revealed that the XPC defects resulted in altered transcriptions for many important apoptosis-related genes, suggesting an important role of the XPC protein in the cisplatin DNA damaging treatment-mediated apoptosis process. Therefore, the genes involved in the apoptotic cell death process were determined using the microarray data (Fig. 3 and Tab. 3). Indeed, the transcription levels for several important apoptosis-related genes were significantly affected by the XPC defect in the cisplatin treatment. In the $\mathrm{NF}$ cells, the cisplatin treatment led to increased transcriptions in caspase-3, caspase-4, caspase-5, and GADD-45A. In the GM16684 XPC cells, however, the degrees of the up-regulation of these genes were significantly reduced with the treatment (Tab. 3). The trans-cription levels of two apoptosis-related genes, brca2 and $E 2 F 1$, were significantly decreased in the cisplatin-treated NF cells. In the GM16684 XPC cells, however, the transcription levels of both genes were only slightly reduced after the treatment (Tab. 3). Interestingly, the transcription levels of the antiapoptosis-related gene $I A P 1$ was decreased in the NF cells but increased in the GM16684 XPC cells with the treat- 
Tab. 3 The cell cycle and apoptosis-related genes that were affected by the XPC defect in the cisplatin treatment

\begin{tabular}{ll}
\hline Gene & \multicolumn{2}{l}{ Fold change with cisplatin treatment } \\
\cline { 2 - 3 } & $\Delta \mathrm{NF} \quad \Delta \mathrm{XPC} \Delta \Delta(\Delta \mathrm{XPC}-\Delta \mathrm{NF})$ \\
\hline
\end{tabular}

\begin{tabular}{|c|c|c|c|}
\hline \multicolumn{4}{|c|}{ 1. Genes involved in cell cycle regulation } \\
\hline $\operatorname{cip} 1^{*}$ & 5.81 & 2.10 & -2.77 \\
\hline$G A D D 45 A^{*}$ & 1.90 & 1.16 & -1.63 \\
\hline$m d m 2$ & 1.67 & -1.01 & -1.69 \\
\hline $\mathrm{mcm} 7^{*}$ & 5.38 & 2.01 & -2.67 \\
\hline bubl & -2.00 & -1.06 & 1.89 \\
\hline$c d c 25 A$ & -2.00 & -1.10 & 1.81 \\
\hline$c d c 25 B$ & -1.83 & -1.09 & 1.68 \\
\hline$c y c A 2$ & -1.95 & 1.02 & 2.00 \\
\hline$c y c B 1$ & -1.60 & 1.01 & 1.61 \\
\hline$c y c D 2$ & -1.96 & -1.19 & 1.64 \\
\hline$c y c E 1$ & -1.54 & 1.18 & 1.82 \\
\hline$c d c 61$ & -1.60 & 1.11 & 1.78 \\
\hline$c d c 45$ & -2.72 & 1.16 & 3.16 \\
\hline$c d k 1^{*}$ & -2.81 & -1.37 & 2.05 \\
\hline$c d k 2$ & -1.51 & 1.04 & 1.57 \\
\hline$c d k 6$ & -1.70 & -1.07 & 1.59 \\
\hline$e 2 f 1$ & -1.94 & -1.06 & 1.84 \\
\hline$m c m 2$ & -3.09 & -1.04 & 2.97 \\
\hline$m c m 5$ & -2.57 & -1.19 & 2.14 \\
\hline PCNA & -1.46 & 1.35 & 1.97 \\
\hline$P L K$ & -1.86 & -1.20 & 1.59 \\
\hline
\end{tabular}

\section{Genes involved in apoptosis}

\begin{tabular}{lrrr} 
brca2 & -1.59 & -1.06 & 1.51 \\
cxcr1 & -2.17 & 1.18 & 2.56 \\
E2F1 & -1.95 & -1.06 & 1.83 \\
$I A P 1$ & -1.18 & 1.95 & 2.30 \\
$I P L$ & 1.35 & 2.57 & 2.13 \\
$M A P T$ & -2.04 & 1.11 & 2.27 \\
casp3 & & & -1.96 \\
casp4 $^{*}$ & & & -1.86 \\
casp5 $_{\text {GADD45A }}^{*}$ & 2.16 & 1.24 & -1.75 \\
\hline
\end{tabular}

The genes labeled with ${ }^{*}$ are the commonly affected genes in both XPC cell lines with the cisplatin treatment.

ment (Tab. 3). In addition, the transcription level of the IPL gene was also significantly affected by the XPC defect in the treatment (Tab. 3). These results suggest that the XPC protein DNA damage recognition signal is involved in the cisplatin DNA damaging treatment-mediated apoptotic cell death process.
Tab. 4 The DNA repair-related genes that were affected by the XPC defect in the cisplatin treatment.

\begin{tabular}{lccc}
\hline \multirow{2}{*}{ Gene } & \multicolumn{3}{c}{ Fold change with cisplatin treatment } \\
\cline { 2 - 4 } & $\Delta \mathrm{NF}$ & $\Delta \mathrm{XPC}$ & $\Delta \Delta(\Delta \mathrm{XPC}-\Delta \mathrm{NF})$ \\
\hline 1. DNA repair & & & \\
gadd45 $^{*}$ & 1.90 & 1.16 & -1.63 \\
gtf2H2 & 1.51 & -1.11 & -1.68 \\
& & & \\
adprt $^{*}$ & -1.65 & 1.00 & 1.66 \\
fancg $^{*}$ & -1.79 & 1.05 & 1.88 \\
lig1 $^{*}$ & -2.34 & -1.05 & 2.23 \\
MGMT $^{*}$ & -1.36 & -2.27 & -1.67 \\
pcna $_{\text {pol } 11^{*}}$ & -1.46 & 1.35 & 1.97 \\
rad51 $^{*}$ & -2.38 & -1.03 & 2.30 \\
rpa3 $^{*}$ & -2.71 & 1.22 & 3.31
\end{tabular}

\section{Double-strand break repair}

$\begin{array}{llll}\text { fen1 } & -1.79 & 1.18 & 2.11 \\ \text { brca2 } & -1.59 & -1.06 & 1.51 \\ \text { pold3 } & -1.66 & -1.05 & 1.59\end{array}$

\section{Mismatch Repair}

$\begin{array}{llrl}m l h 1^{*} & -1.52 & -1.03 & 1.50 \\ m s h 2 & -1.89 & -1.22 & 1.55 \\ m s h 6 & -1.83 & 1.05 & 1.90\end{array}$

4. Nucleotide excision repair
$\begin{array}{lccc}\text { xpc } & 1.57 & -1.58 & -2.49 \\ \text { hchl-1/krg2 } & -2.58 & -1.01 & 2.56\end{array}$

\section{DNA modification}

\section{\begin{tabular}{llll}
$\mathrm{NP}$ & 1.81 & 5.82 & 3.22 \\
\hline
\end{tabular} \\ The genes labeled with * are the commonly affected genes in both XPC cell lines with the cisplatin treatment. \\ The role of the XPC protein in the cisplatin DNA damaging treatment-mediated $\mathrm{DNA}$ repair}

As a result of the important function of the XPC protein DNA damage recognition in the initiation of the DNA repair process, we further determined the DNA repair genes that were affected by the XPC defect in the cisplatin treatment (Fig. 4 and Tab. 4). Interestingly, many important DNA repair genes relating to different DNA repair pathways were significantly affected by the XPC defect in the cisplatin treatment. In the double-strand break (DSB) DNA repair pathway, three genes, fen 1, brca 2 , and $p o l \delta 3$, were down- 
Hs_apoptosis

Expression dataset

Name: All SAM signigicant delta delta

Gene ColorSet: delta delta

Gene Value: delta delta

\begin{tabular}{|c|}
\hline ABS \\
\hline ACRP \\
\hline ADORA2A \\
\hline ADRA1A \\
\hline AGTR2 \\
\hline AHR \\
\hline APAF1 \\
\hline APG12L \\
\hline APG5L \\
\hline APP \\
\hline APR2 \\
\hline ARHGEF6 \\
\hline AXIN1 \\
\hline BAG2 \\
\hline BAG3 \\
\hline BAG5 \\
\hline BCL2L1 \\
\hline BCLG \\
\hline BID \\
\hline BOK \\
\hline BRCA1 \\
\hline BRCA2 \\
\hline CASP3 \\
\hline
\end{tabular}

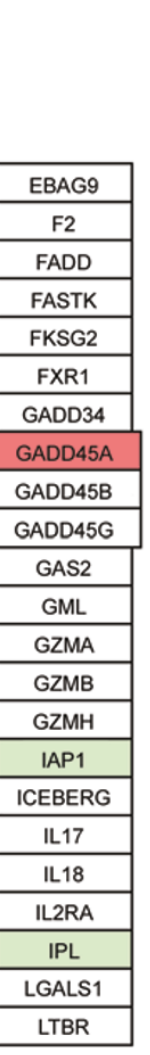

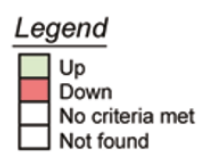

\begin{tabular}{|c|}
\hline MAP3K5 \\
\hline MAPT \\
\hline MCL1 \\
\hline MIH1/TX \\
\hline MKPX \\
\hline NALP2 \\
\hline NCKAP1 \\
\hline NFKB1A \\
\hline NGFR \\
\hline NGFRAP1 \\
\hline NME6 \\
\hline 048 \\
\hline P2RX1 \\
\hline P53AIP1 \\
\hline P63 \\
\hline PAX3 \\
\hline PDCD1 \\
\hline PDCD2 \\
\hline PDCD6 \\
\hline PDCD8 \\
\hline PDE1B \\
\hline PEA15 \\
\hline PED \\
\hline
\end{tabular}

\begin{tabular}{|c|}
\hline PGLYRP \\
\hline PNUTL2 \\
\hline PRKR \\
\hline PRSS25 \\
\hline PTK2B \\
\hline PTPN6 \\
\hline RAF1 \\
\hline RTN4 \\
\hline SARP3 \\
\hline SIAH1 \\
\hline STK3 \\
\hline TEGT \\
\hline TNFAIP3 \\
\hline TNFRSF10A \\
\hline TNFRSF10B \\
\hline TNFRSF10AC \\
\hline TNFRSF10D \\
\hline TNFRSF1A \\
\hline TNFSF7 \\
\hline TNFSF9 \\
\hline TP53 \\
\hline TP73 \\
\hline TXNL \\
\hline YARS \\
\hline
\end{tabular}

Fig. 3 The effect of the XPC defect on transcription of apoptosis-related genes in the cisplatin treatment. The net fold change of genes $(\Delta \Delta$ between the XPC and NF cells with the cisplatin treatment were used to determine the pattern of gene transcription regulation $(\Delta \Delta \geq 1.5)$. When $\Delta \Delta>0$, the gene is counted as up regulated (colored green in the map). When $\Delta \Delta<0$, the gene is counted as down regulated (colored red in the map). If $\Delta \Delta<1.5$ or if no data is available from the microarray analysis, the gene is uncolored in the map.

regulated in the treated NF cells. In the treated XPC cells, however, the degree of down-regulation was attenuated (Fig. 4 and Tab. 4). In the mismatch repair (MMR) pathway, the transcription response of three important genes, $m l h l$, $m s h 2$, and $m s h 6$, were also affected by the XPC defects in the treatment. In the NER pathway, the transcriptions of the $x p c$ and $H C H L-1 / K R G 2$ genes were affected with the XPC defects in the treatment; all other important NER genes, including $x p a, x p g$, and $x p f$, were unaffected by the XPC defect with the treatment. In addition, the transcriptions of several other DNA repair-related genes, including rpa3, rad51, fancg, adprt, lig1, and pold1, were also altered by the XPC defect in the treatment. These results suggest a very broad role of the XPC protein in many different DNA repair processes with the cisplatin treatment. Interestingly, none of the base excision repair (BER) genes were affected by the XPC defect in the treatment.

\section{The XPC defect and attenuated caspase-3 activation with the cisplatin treatment}

The results obtained from the microarray data strongly suggest that the XPC protein plays an important role in the cisplatin DNA damaging treatment-mediated cell cycle regulation, resulting in apoptotic cell death. To validate the microarray data, we determined the cisplatin treatmentmediated caspase-3 activation (Fig. 5). Caspase-3 is a key caspase that directly cleaves other proteins and causes apoptotic cell death. Therefore, activation of the caspase-3 is an important indicator of apoptosis. The cisplatin treatment led to an increase in the active caspase- 3 when the NF cells were treated with $20 \mu \mathrm{M}$ cisplatin for 24 and 48 h. In contrast, no significant change was seen for the active caspase- 3 in the cisplatin-treated XPC cells for as long as 48 $\mathrm{h}$. These results suggest that the XPC protein plays an important role in the cisplatin treatment-mediated apop-totic 
Hs_DNA repair

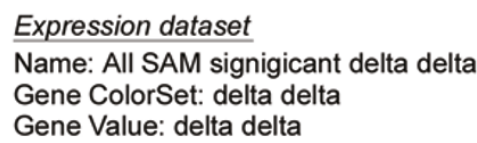

\begin{tabular}{|c|}
\hline 51C Protein \\
\hline ADPRT \\
\hline ADPRTL1 \\
\hline ADPRTL3 \\
\hline ATM \\
\hline ATR \\
\hline ATRX \\
\hline BLM \\
\hline BTG2 \\
\hline CCNH \\
\hline CDK7 \\
\hline CHAF1A \\
\hline CHAF1B \\
\hline CKN1 \\
\hline CSNK1D \\
\hline CSNK1E \\
\hline DDB1 \\
\hline DDB2 \\
\hline DINB1 \\
\hline DMC1 \\
\hline DNTT \\
\hline ERCC1 \\
\hline ERCC6 \\
\hline EXO1 \\
\hline FANCA \\
\hline FANCC \\
\hline FANCG \\
\hline FRAP1 \\
\hline
\end{tabular}

\begin{tabular}{|c|}
\hline GADD45A \\
\hline GADD34G \\
\hline GTF2H2 \\
\hline GTF2H4 \\
\hline HEX1 \\
\hline HUS1-like \\
\hline IGHMBP2 \\
\hline KIAA0216 \\
\hline KIAA0658 \\
\hline LIG1 \\
\hline LIG3 \\
\hline MBD4 \\
\hline MNAT1 \\
\hline MEN \\
\hline NUDT1 \\
\hline PCNA \\
\hline PHLL1 \\
\hline POLB \\
\hline POLD1 \\
\hline POLE \\
\hline POLE2 \\
\hline POLG2 \\
\hline POLL \\
\hline POLQ \\
\hline PP13 \\
\hline RAD17 \\
\hline RAD17 \\
\hline RAD17 \\
\hline
\end{tabular}

Base excision repair

\begin{tabular}{|c|}
\hline APEX1 \\
\hline DKFZP586 \\
\hline HMYH \\
\hline MPG \\
\hline OCTS3 \\
\hline OGG1 \\
\hline OGG1-1E \\
\hline TDG \\
\hline UNG \\
\hline UNG2 \\
\hline
\end{tabular}

DNA DE-Alkylation

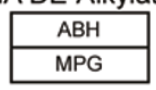

DNA Ligation

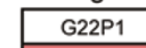

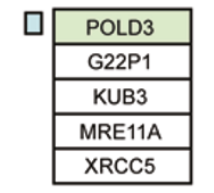

Mismatch repair

\begin{tabular}{|c|}
\hline ABL1 \\
\hline DKFZP434 \\
\hline G7 \\
\hline HPMSR2 \\
\hline KIAA1413 \\
\hline MLH1 \\
\hline MLH3 \\
\hline MSH2 \\
\hline MSH3 \\
\hline MSH4 \\
\hline MSH5 \\
\hline MSH6 \\
\hline PMS1 \\
\hline PMS2 \\
\hline PMS4 \\
\hline PMS5 \\
\hline PMS6 \\
\hline PMS7 \\
\hline PMS8 \\
\hline POLD3 \\
\hline TP73 \\
\hline
\end{tabular}

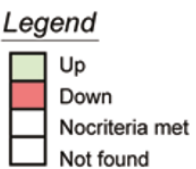

Nucleotide excision repair

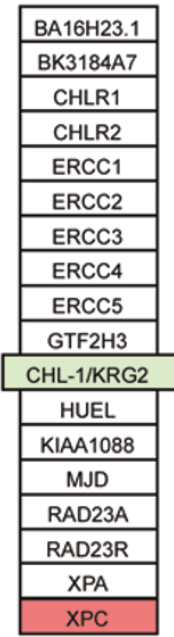

Post-Replication repair

\begin{tabular}{|c|}
\hline CIB1 \\
\hline FEN1 \\
\hline NBS1 \\
\hline PRKDC \\
\hline RAD50 \\
\hline RAD52 \\
\hline XRCC4 \\
\hline BRCA2 \\
\hline
\end{tabular}

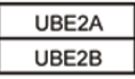

Regulation of DNA repair

\begin{tabular}{|c|}
\hline KARP1 \\
\hline MMS2 \\
\hline XPV \\
\hline
\end{tabular}

Fig. 4 The effect of the XPC defect on transcription of DNA repair genes with the cisplatin treatment. The net fold change of genes $(\Delta \Delta$ between the XPC and NF cells with the cisplatin treatment were used to determine the pattern of gene transcription regulation $(\Delta \Delta \geq 1.5)$. When $\Delta \Delta>0$, the gene is counted as up regulated (colored green in the map). When $\Delta \Delta<0$, the gene is counted as down regulated (colored red in the map). If $\Delta \Delta<1.5$ or if no data is available from the microarray analysis, the gene is uncolored in the map.

cell death and that the XPC defects resulted in a reduction in the cisplatin treatment-mediated apoptosis.

\section{The involvement of p53 protein in the cisplatin DNA damaging treatment-mediated signaling process}

Although the results obtained from our microarray data and western blot results suggest an important role of the XPC protein in the cisplatin DNA damaging treatmentmediated cell cycle regulation, the signaling pathways involved in this process are unknown. To elucidate the involvement of $\mathrm{p} 53$-related signal transduction pathway in this process, we have determined the cisplatin treatmentmediated p53 response (Fig. 6). The level of p53 protein was significantly increased when NF cells were treated with cisplatin for $16 \mathrm{~h}$ or longer (Fig. 6 lanes 6 and 7 vs lane 1). In contrast, when XPC cells were treated with cisplatin under the same condition, the degree of increase of the p53 protein was greatly attenuated (Fig. 6 lanes 13 and 14 vs lanes 6 and 7). This result suggests that the p53-related signaling pathway is indeed involved in the XPC protein DNA damage recognition-mediated signal transduction process.

\section{DISCUSSION}

In this study, we have determined the role of the XPC protein in cisplatin DNA damaging treatment-mediated cellular response. Comparison of the microarray data obtained in both the NF and XPC cells identified 861 genes with altered transcription responses with the XPC defect in the cisplatin treatment (minimal fold change $\geq 1.5$ ). The 


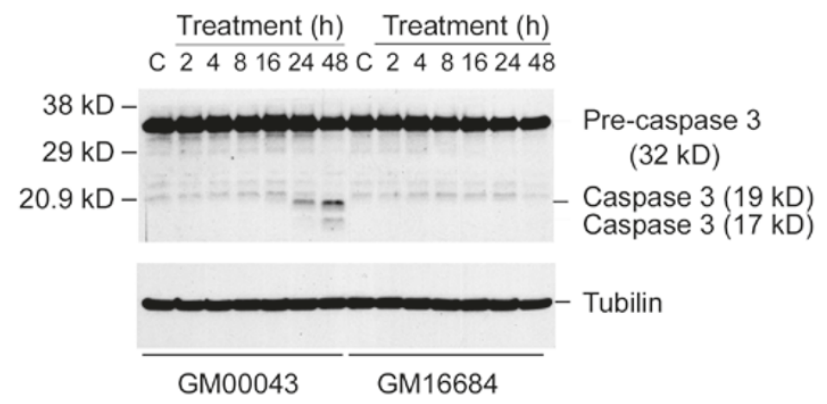

Fig. 5 Cisplatin treatment-mediated caspase-3 activation in both NF and XPC cells. Both the NF and XPC cells were treated with cisplatin at $20 \mu \mathrm{M}$ for various lengths of time (h). The cells were lysed and analyzed by western blot hybridization assay for the level of active caspase-3 (19 kD and $17 \mathrm{kD})$. Cell lyses of the untreated cells (c) were used to determine the background level of caspase- 3 in each cell line.

RT-PCR based real time PCR results further confirmed the consistency of the results, indicating a high reliability of the microarray data obtained in this study. These results suggest that the XPC protein plays an important role in the cisplatin DNA damaging treatment-mediated cellular response. Therefore, the results obtained from this study provide an important understanding for the mechanism of cisplatin treatment-mediated cellular response and the role of the XPC protein in this process.

The transcription responses of many cell cycle and cell proliferation-related genes were greatly affected by the XPC defect in the cisplatin treatment, suggesting an important role of the XPC protein in the cisplatin treatmentmediated cell cycle arrest and apoptosis. This provides some important insights into the mechanism of bulky DNA damage mediated cell cycle arrest and apoptosis. Although many DNA damaging reagents, including many commonly used anticancer drugs, can generate bulky DNA damage and cause cell death, the mechanism of this process is not fully understood. More importantly, the proteins that can recognize the bulky DNA damage and initiate the signaling process have not been identified in human cells. XPC, an important DNA damage recognition protein for nucleotide excision repair (NER), is an ideal protein candidate to initiate this signaling process. The XPC protein recognizes a variety of bulky DNA damages [9-16, 36, 37]. The XPCHR23B complex is also the first protein component that binds to the damaged sites [23-25]. In addition, the XPC protein is known to interact with several important protein components including the basal transcription factor TFIIH and the centrisomal protein CEN2 [18-22]. It is likely that some of these interactions initiate the DNA damagemediated signaling process, resulting in cell cycle arrest
A Time of cisplatin treatment $(\mathrm{h})$

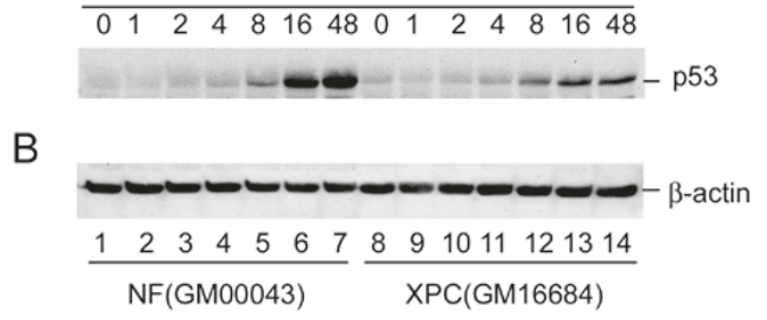

Fig. 6 Detection of the p53 protein in both the NF and XPC cells with the cisplatin treatment. Both the NF (GM00043) and XPC (GM16684) cells were treated with cisplatin $(20 \mu \mathrm{M})$ for various lengths of times. The cell lyses were analyzed by Western blot hybridization assay for the levels of p53 protein. (A) The level of p53 protein during the cisplatin treatment. (B) The level of $\beta$-actin during the cisplatin treatment. Both the p53 and $\beta$-actin were detected from the same membrane.

and apoptotic cell death. For example, it is known that the XPC-TFIIH complex formation exists in the cells and the TFIIH interacts with the $\mathrm{p} 53$ protein [38-40]. It is possible that the DNA damage recognition of the XPC protein may influence the XPC-TFIIH complex formation and affect the interaction of the TFIIH with p53 protein, resulting in activation of the p53-related signal transduction pathway and subsequent DNA repair and apoptosis. Further studies are needed to determine the molecular mechanism on how the XPC protein DNA damage recognition signal leads to cell cycle arrest and apoptosis.

We have studied the role of the XPC protein in the cisplatin DNA damage-mediated DNA repair process. Although the XPC protein was identified as a DNA damage recognition protein for the NER pathway [7, 8], the results obtained from our microarray data analysis suggest a much broader role of the XPC protein in the DNA repair process. In the MMR pathway, for example, the transcription responses of three important MMR genes ( $m l h 1, m s h 2$, and $m s h 6$ ) were greatly affected by the XPC defect in the cisplatin treatment, suggesting an important role of the XPC protein DNA damage recognition signal in the regulation of the MMR pathway. In the double-strand break (DSB) DNA repair pathway, the transcription responses of fen-1, brca 2 , and pol $\delta 3$ were also affected by the XPC defect in the treatment, suggesting a possible role of the XPC protein DNA damage recognition signal in the regulation of the DSB pathway. In addition, many other important DNA repair genes were also affected by the XPC defects in the cisplatin treatment. All these results suggest that the XPC protein DNA damage recognition signal may be involved in the regulation of many different DNA repair pathways. Interestingly, none of the BER genes were affected by the 
XPC defect in the treatment, suggesting an unimportant role of the XPC protein DNA damage recognition signal in regulation of the BER pathway.

The XPC defects have been associated with many types of cancer [26-29]. The results obtained from our recent mutagenesis study demonstrated that the XPC defect led to an increase in mutation accumulation [14]. The results obtained from this study further suggest that the XPC protein is involved in DNA damage-mediated cell cycle arrest and apoptosis. Collectively, these results strongly suggest that the XPC protein plays a critical role in preventing cancer occurrence by recognizing DNA damage and initiating the DNA damage-mediated signaling process, resulting in the removal of DNA damage in the genome or elimination of the damaged cells by the apoptotic process. Therefore, these results provide important under-standings for cancer occurrence, prevention, diagnosis, treatment, and anticancer drug design and development.

\section{ACKNOWLEDGEMENT}

We thank X ZHANG for her experimental assistance. We also thank Drs. R Novak and P Stemmer for their helpful discussions and critical readings of this manuscript and R. Paxton for his critical readings of this manuscript. Performance of this work was facilitated by the Cell Culture Core and the Microarray and Bioinformatic Cores of the Environmental Health Sciences Center in Molecular and Cellular Toxicology with Human Applications at Wayne State University (P30 ES06639). This work is supported by a grant R01ES09699 from the National Institute of Environmental Health Sciences, NIH to G Wang and a pilot project from the Environmental Health Sciences Center at Wayne State University (P30 ES06639).

\section{Received, April 6, 2004}

Revised, Jun 15, 2004

Accepted, Jun 22, 2004

\section{REFERENCES}

1 Sanchez Y, Bachant J, Wang H, et al. Control of the DNA damage checkpoint by chk1 and rad53 protein kinases through distinct mechanisms. Science 1999; 286:1166-71.

2 Wakasugi M, Sancar A. Order of assembly of human DNA repair excision nuclease. J Biol Chem 1999; 274:18759-68.

3 Batty DP, Wood RD. Damage recognition in nucleotide excision repair of DNA. Gene 2000; 241:193-204.

4 Zou L, Elledge SJ. Sensing DNA damage through ATRIP recognition of RPA-ssDNA complexes. Science 2003; 300:1542-8.

5 Kaufmann WK, Paules RS. DNA damage and cell cycle checkpoints. FASEB J 1996; 10:238-47.

6 Shackelford RE, Kaufmann WK, Paules RS. Cell cycle control, checkpoint mechanisms, and genotoxic stress. Environ Health Perspect 1999; 107:5-24.

7 Legerski R, Peterson C. Expression cloning of a human DNA repair gene involved in xeroderma pigmentosum group C. Nature 1992; 359:70-3.

8 Friedberg EC, Walker GC, Siede W. DNA repair and mutagenesis. Washington DC: ASM, 1995.

9 Emmert S, Kobayashi N, Khan SG, Kraemer KH. The xeroderma pigmentosum group $\mathrm{C}$ gene leads to selective repair of cyclobutane pyrimidine dimers rather than 6-4 photoproducts. Proc Natl Acad Sci USA 2000; 97:2151-6.

10 Batty D, Rapic'-Otrin V, Levine AS, Wood RD. Stable binding of human XPC complex to irradiated DNA confers strong discrimination for damaged sites. J Mol Biol 2000; 300:275-90.

11 Wang G, Chen Z, Zhang S, Wilson GL, Jing K. Detection and determination of oligonucleotide triplex formation-mediated transcription-coupled DNA repair in HeLa nuclear extracts. Nucleic Acids Res 2001; 29:1801-7.

12 Janicijevic A, Sugasawa K, Shimizu Y, et al. DNA bending by the human damage recognition complex XPC-HR23B. DNA Repair 2003; 2:325-36.

13 Masson C, Menaa F, Pinon-Lataillade G, et al. Global genome repair is required to activate KIN17, a UVC-responsive gene involved in DNA replication. Proc Natl Acad Sci USA 2003; 100:616-21.

14 Chen ZW, Xu XS, Yang J, Wang G. Defining the function of XPC protein in psoralen and cisplatin-mediated DNA repair and mutagenesis. Carcinogenesis 2003; 24:1111-21.

15 Wang A, Gu J, Judson-Kremer K, et al. Response of human mammary epithelial cells to DNA damage induced by BPDE: involvement of novel regulatory pathways. Carcinogenesis 2003; 24:225-34.

16 Wijnhoven SW, Kool HJ, Mullenders LH, Slater R, van Zeeland AA, Vrieling H. DMBA-induced toxic and mutagenic responses vary dramatically between NER-deficient Xpa, Xpc and Csb mice. Carcinogenesis 2001; 22:1099-106.

17 Masutani C, Sugasawa K, Yanagisawa J, et al. Purification and cloning of a nucleotide excision repair complex involving the xeroderma pigmentosum group $\mathrm{C}$ protein and a human homologue of yeast RAD23. EMBO J 1994; 13:1831-43.

18 van der Spek PJ, Eker A, Rademakers S, et al. XPC and human homologs of RAD23: intracellular localization and relationship to other nucleotide excision repair complexes. Nucleic Acids Res 1996; 24:2551-9.

19 Li L, Lu X, Peterson C, Legerski R. XPC interacts with both HHR23B and HHR23A in vivo. Mutation Res 1997; 383:197203.

20 Sugasawa K, Masutani C, Uchida A, et al. HHR23B, a human Rad23 homolog, stimulates XPC protein in nucleotide excision repair in vitro. Mol Cell Biol 1996; 16:4852-61.

21 Araki M, Masutani C, Takemura M, et al. Centrosome protein centrin 2 /caltractin 1 is part of the xeroderma pigmentosum group $\mathrm{C}$ complex that initiates global genome nucleotide excision repair. J Biol Chem 2001; 276:18665-72.

22 Wang Q, Zhu Q, Wani MA, Wani G, Chen J, Wani AA. Tumor suppressor p53 dependent recruitment of nucleotide excision repair factors XPC and TFIIH to DNA damage. DNA Repair 2003; 2:483-99.

23 Wood RD. DNA damage recognition during nucleotide excision repair in mammalian cells. Biochimie 1999; 81:39-44.

24 Volker M, Mone MJ, Karmakar P, et al. Sequential assembly of the nucleotide excision repair factors in vivo. Mol Cell 2001; 
8:213-24.

25 Sugasawa K, Okamoto T, Shimizu Y, Masutani C, Iwai S, Hanaoka F. A multistep damage recognition mechanism for global genomic nucleotide excision repair. Genes Dev 2001; 15:507-21.

26 Takebayashi Y, Nakayama K, Kanzaki A, et al. Loss of heterozygosity of nucleotide excision repair factors in sporadic ovarian, colon and lung carcinomas: implication for their roles of carcinogenesis in human solid tumors. Cancer Lett 2001; 174:115-25.

27 Miyashita H, Mori S, Tanda N, et al. Loss of heterozygosity of nucleotide excision repair factors in sporadic oral squamous cell carcinoma using microdissected tissue. Oncol Rep 2001; 8:1133-8.

28 Goode EL, Ulrich CM, Potter JD. Polymorphisms in DNA repair genes and associations with cancer risk. Cancer Epidemiol Biomarkers \& Prev 2002; 11:1513-30.

29 Chang YH, Wu YH, Chen CY, Lai SL, Lee H. XPC mRNA is a favorable prognostic factor in non-smoking non-small cell lung cancer patients. Proceedings, 93rd Annual Meeting of American Association for Cancer Research 2002; 43:1030.

30 Cheo DL, Burns DK, Meira LB, Houle JF, Friedberg EC. Mutational inactivation of the xeroderma pigmentosum group $\mathrm{C}$ gene confers predisposition to 2-acetylaminofluorene-induced liver and lung cancer and to spontaneous testicular cancer in Trp53-/-mice. Cancer Res 1999; 59:771-5.

31 Friedberg EC, Cheo DL, Meira LB, Reis AM. Cancer predisposition in mutant mice defective in the XPC DNA repair gene. Prog Exp Tumor Res 1999; 35:37-52.

32 Inga A, Nahari D, Velasco-Miguel S, Friedberg EC, Resnick MA. A novel p53 mutational hotspot in skin tumors from UV-irradiated Xpc mutant mice alters transactivation functions. Oncogene
2002; 21:5704-15.

33 Tusher GT, Tibshirani R, Chu G. Significance analysis of microarrays applied to the ionizing radiation response. Proc Natl Acad Sci USA 2001: 8:5116-21.

34 Uchida A, Sugasawa K, Masutani C, et al. The carboxy-terminal domain of the XPC protein plays a crucial role in nucleotide excision repair through interactions with transcription factor IIH. DNA Repair 2002; 1:449-61.

35 Ashburner M, Ball CA, Blake JA, et al. Gene Ontology: tool for the unification of biology. The Gene Ontology Consortium. Nat Genet 2000; 25:25-9.

36 Zhou NY, Bates SE, Bouziane M, Stary A, Sarasin A, O’Connor TR. Efficient repair of cyclobutane pyrimidine dimers at mutational hot spots is restored in complemented xeroderma pigmentosum group $\mathrm{C}$ and trichothiodystrophy/xeroderma pigmentosum droup D cells. J Mol Biol 2003; 332:337-51.

37 Fitch ME, Nakajima S, Yasui A, Ford JM. In vivo recruitment of XPC to UV-induced cyclobutane pyrimidine dimers by the DDB2 gene product. J Biol Chem 2003; 278:46906-10.

38 Leveillard T, Andera L, Bissonnette N, et al. Functional interactions between p53 and the TFIIH complex are affected by tumour-associated mutations. EMBO J 1996; 15:1615-24.

39 Ko LJ, Shieh SY, Chen X, et al. p53 is phosphorylated by CDK7cyclin H in a p36MAT1-dependent manner. Mol Cell Biol 1997; 17:7220-9.

40 Lu H, Fisher RP, Bailey P, Levine AJ. The CDK7-cycH-p36 complex of transcription factor IIH phosphorylates p53, enhancing its sequence-specific DNA binding activity in vitro. Mol Cell Biol 1997; 17:5923-34. 
Retraction notice

The involvement of XPC protein in the cisplatin DNA damaging treatment-mediated cellular responses Gan WANG*, Alan DOMBKOWSKI, Lynn CHUANG, Xiao Xin XU

Institute of Environmental Health Sciences, Wayne State University, 2727 Second Avenue, Detroit, MI 48201, USA Published in: Cell Res 2004; 14:303-14.

Due to some concern regarding the scientific overlap between the papers that we published in Cell Research (Cell Res 2004; 14:30314.) and the paper that we published in the Nucleic Acids Research (Nucleic Acids Res 2004; 32:2231-40.), we hereby retract the paper that we published in Cell Research, even though the data in the Cell Research paper is scientifically valid. We apologize for any inconvenience that this may have caused.

Gan WANG 